ISSN: 1838-3815 (online) Journal Homepage: https://ojs.deakin.edu.au/index.php/itlge/

\title{
Evaluation of a leadership development program to enhance university staff and student resilience
}

\author{
Margo Brewer ${ }^{1}$, Murray Lane ${ }^{2}$, Alice Carter ${ }^{1}$, Sue Barnard ${ }^{3}$ and Omar Ibrahim ${ }^{4}$ \\ Corresponding author: Margo Brewer (m.brewer@curtin.edu.au) \\ ${ }^{1}$ Faculty of Health Sciences, Curtin University \\ ${ }^{2}$ Division of Research and Innovation, Queensland University of Technology \\ ${ }^{3}$ Equity and Student Counselling Department, Queensland University of Technology \\ ${ }^{4}$ Faculty of Health, Queensland University of Technology
}

\begin{abstract}
University life presents challenges that can negatively affect the health and wellbeing of students and staff. Resilience is critical to managing challenges and thus is increasingly viewed as important for university students, graduates and employees. To date research on resilience has tended to adopt a view of resilience as an individual issue with little consideration of the socio-cultural factors that influence an individual's resilience. To address this gap a leadership program to enhance both staff resilience and their capacity to lead resilience enhancements for students from an ecological perspective was developed. The program, piloted in three universities across Australia, assisted staff in understanding the nature and importance of resilience, the contextual factors that impact on resilience and the leadership practices that help drive change in the higher education context. Both academic staff and professional staff involved in leading co-curricula student experiences participated in the two-day leadership program. This study, part of a broader program evaluation, adopted a mixed methods approach to investigate university staffs' levels of distress, resilience, and leadership practices. Pre- and post-intervention survey data indicated the program was positively received and most participants felt confident to lead curricula and co-curricula changes to enhance resilience within their work context. Implications for university educators, researchers and leaders are discussed.
\end{abstract}

\section{Introduction}

Concern over university student distress has been on the rise in recent years in Australia (Stallman, 2011) and across the globe (Larcombe et al., 2016). Stressors reported by students include academic workload demands, difficulty balancing study with employment and financial pressures (Ryan, Shochet, \& Stallman, 2010). In their recent study on Australian university students, Stallman and Hurst (2016) highlighted that while a degree of stress is associated with arousal and performance, excessive stress coupled with poor coping skills, contributes to psychological distress and mental health problems. This study found that $60 \%$ of over 2,500 students reported feeling distressed (Stallman \& Hurst, 2016). Similarly, Larcombe and colleagues (2016) large scale study involving 4,258 Australian university students found one in four reported severe psychological distress. Symptoms

Brewer, M., Lane, M., Carter, A., Barnard, S., \& Ibrahim, O. (2019). Evaluation of a leadership development program to enhance university staff and student resilience. Journal of Teaching and Learning for Graduate Employability, 10(2), $136-151$. 
of distress include fatigue, hopelessness, depression, loss of energy and worthlessness (Sunderland, Mahoney, \& Andrews, 2012). Elevated student stress can be detrimental not only to student health but also learning outcomes (Watson, Deary, Thompson, \& Li, 2008). For instance, the most common reasons for student attrition across Australian universities in 2015 included physical and mental health issues and financial pressures (Higher Education Standards Panel, 2017).

In response to this concern over university student distress and mental health problems, the development of strategies to enhance student resilience is gaining importance in higher education with resilience described as a vital capability for students to develop (Dickinson \& Dickinson, 2015; Holdsworth, Turner, \& Scott-Young, 2018). Resilience has been defined as a dynamic process of positive adaptation in the face of adversity or challenge. This process involves the capacity to negotiate for and draw upon psychological, social, cultural and environmental resources (Brewer et al., 2019, p. 10). The development of resilience has been shown to reduce psychological distress, assist with managing academic demands and enhance academic outcomes (Ortega-Maldonado, \& Salanova, 2018; Pidgeon, Rowe, Stapleton, Magyar, \& Lo, 2014). Rahat and Ilhan (2016) describe resilience as a significant predictor of successful coping for university students. Further to this, research has demonstrated that a higher rate of resilience in university students is the best predictor of successful coping (McLafferty, Mallet, \& McCauley, 2012). Therefore, resilience plays an important role in improving students' university experience and preparing them for contemporary work environments where coping with ongoing change and stress is critical (Humburg, Van der Velden, \& Verhagen, 2013; Ovans, 2015).

University staff play a pivotal role in the development of student capabilities (Chalmers et al., 2014), and thus are ideally placed to help build students' resilience (Ortega-Maldonado \& Salanova, 2018). However, barriers exist to staff successfully enhancing student resilience, including the pressures they face on a daily basis. Hoffman (2017) cites administrative overload, large student cohorts, time constraints and unrealistic workload demands as key challenges for academics. Bahia, Freire, Estrela, Amaral, and Santo (2017) discuss the negative impact of increased bureaucratisation of higher education on academics' work and emotions. Behari-Leak (2017) highlights the constant state of flux in the university work environment as institutions strive to address demands for increased efficiency, accountability and quality. In the context of these organisational changes, as well as the demand to demonstrate high level administrative, managerial, scholarly and entrepreneurial skills (Zabrodska et al., 2018), academic teaching is increasingly associated with distress and burnout (Watts \& Robertson, 2011). These experiences can not only hinder the implementation of new pedagogical initiatives but also impact on the resilience of staff. The critical role of resilience for academic staff is highlighted by Gu and Day (2013) who claim to teach, and to teach at one's best over time, has always required resilience (p. 22). Furthermore, staff need to role-model resilience (Holdsworth et al., 2018).

The pedagogical changes needed to enhance student resilience require staff to develop new classroom practices, to rethink curriculum design (Ortega-Maldonado \& Salanova, 2018; Mula et al., 2017), and to develop their ability to influence the educational practice of others. In other words, there is a need for professional development that invites university staff to embed resilience into the existing educational system, to reflect on, rethink and reframe their priorities for, and approaches to, teaching, and to facilitate their leadership of change at the program/course, school or institutional level (Martensson \& Roxa, 2016). Leadership, from this perspective, is defined as the process of influencing others to understand and agree about what needs to be done and how it can be done effectively (Willumsen, 2006, p. 404).

Developing staffs' resilience and capabilities for enhancing student resilience and leading change is an imperative in higher education pedagogy. While there is evidence highlighting positive benefits of various resilience training interventions (Brewer et al., 2019), to date these programs lack methodological quality (Leppin et al., 2014). One example of good practice in the area of training resilience is the Building Resilience in Teacher Education model (Mansfield, Beltman, WeatherbyFell, \& Broadley, 2016). This program aimed to assist pre-service teachers build their resilience by

Brewer, M., Lane, M., Carter, A., Barnard, S., \& Ibrahim, O. (2019). Evaluation of a leadership development program to enhance university staff and student resilience. Journal of Teaching and Learning for Graduate Employability, 10(2), $136-151$. 
providing a series of online learning modules informed by empirical research (Mansfield et al., 2016). While this program supported and trained future school teachers, there is little evidence of programs targeting university students from other disciplines. Further to this, the focus to date has been on viewing resilience as an individual issue with limited consideration of the broader context within which that individual learns or works (Brewer et al., 2019). To address these gaps, this paper describes a multidisciplinary leadership development program that aimed to enhance the resilience of university staff and ultimately their students. Informed by Kirkpatrick and Kirkpatrick's (2006) evaluation model, the specific research questions addressed in this study focused on the first two levels of this model: (1) What aspects of the leadership development program did university staff find satisfactory and useful? (Level 1, reaction), and (2) What impact did the program have on staffs' perceptions of their own resilience, distress, leadership confidence and practice? (Level 2, learning). Evidence of program outcomes at Kirkpatrick and Kirkpatrick's (2006) other two levels have also been measured (participants' behaviour changes and the impact of the program on students' resilience), resulting in a series of manuscripts. The study reported here, the first in the series, outlines the short-term quantitative and qualitative outcomes of the program for 58 staff participants across three Australian universities.

\section{Methodology}

\section{Intervention program}

An intensive leadership development program was developed by a multidisciplinary team of academic and professional staff from three Australian universities; Curtin University (Curtin), University of South Australia (UniSA) and Queensland University of Technology (QUT). The program was informed by quality practice in staff development (Boud \& Brew, 2013; Steinert, Naismith, \& Mann, 2012). For example, the program was underpinned by a needs assessment (pre-intervention survey), considered the participants work context, fostered effective peer relationships, established communities of practice, provided opportunities to reflect on personal goals and learning, and included in-situ mentoring and feedback related to progress and overcoming challenges. Vilkinas and Cartan's (2006) academic leadership model, the Integrated Competing Values Framework, was a core element of the program. The overarching learning outcomes for the staff program were to:

- Enhance participants' understanding of resilience and leadership within the higher education context.

- Develop the capacity of participants, and ultimately their students, to manage the complexities of the 21st Century workplace through enhancing resilience.

- Develop participants' leadership capabilities to embed resilience enhancement strategies within the curriculum.

The program was delivered as a face-to-face course over two consecutive days. The lead author (MB) led the development of the program and facilitated the first pilot. To ensure the future flexibility of the program's delivery, the content was broken into several modules as outlined in Table 1. Modules one to four were delivered on the first day; the remainder carried over to the second day. For a detailed description of the program, along with the program resources, visit the project's website www.enhancingresilience.com. Following the workshops staff continued to receive support in implementing their action plan via peer coaching groups comprised of 4 to 6 members; each group with a mentor from the project team. 
Table 1: Program Modules and their Aims

\begin{tabular}{|c|c|c|}
\hline Module & Title & Aims \\
\hline 1. & $\begin{array}{l}\text { Overview of program and } \\
\text { participants }\end{array}$ & $\begin{array}{l}\text { - Understand the program objectives and structure } \\
\text { - Understand the role of the facilitator(s) and } \\
\text { participants }\end{array}$ \\
\hline 2. & Setting the scene & $\begin{array}{l}\text { - Examine the contemporary higher education } \\
\text { environment } \\
\text { - Understand the drivers for resilience enhancement in } \\
\text { higher education }\end{array}$ \\
\hline 3. & $\begin{array}{l}\text { Conceptualisation of } \\
\text { resilience }\end{array}$ & $\begin{array}{l}\text { - Reflect on own conceptualisation of, and experience } \\
\text { with, resilience } \\
\text { - Understand historical views of resilience } \\
\text { - Define resilience }\end{array}$ \\
\hline 4. & Enhancing resilience & $\begin{array}{l}\text { - Critique resilience intervention research } \\
\text { - Understand key approaches to resilience enhancement } \\
\text { - } \text { ithin an ecological framework } \\
\text { - Critique resources related to resilience enhancement }\end{array}$ \\
\hline 5. & Mindset & - Consider mindset as a factor in enhancing resilience \\
\hline 6. & Leadership & $\begin{array}{l}\text { - Reflect on own conceptualisation of, and experience } \\
\text { with, leadership } \\
\text { - Understand contemporary approaches to leadership } \\
\text { - Consider sustainable change supports including } \\
\text { networking, peer coaching and mentoring } \\
\text { - Create an action plan to lead change }\end{array}$ \\
\hline
\end{tabular}

Eight project team members attended the first pilot in keeping with the train-the-trainer approach adopted. A total of 58 staff ( 48 females, 10 males) participated in the three pilots between August and November 2017; 24 at Curtin, 19 at UniSA, and 15 at QUT. Six staff (10\%) only participated in the first day of the program.

\section{Procedure}

An invitation to attend the program was disseminated via the respective university email channels, accompanied by an information sheet providing the details of the study. Adopting a holistic view of students' university experience, participation was open to both academic and professional staff who had influence over either curricula or co-curricula elements of university life. Participants who registered a desire to participate in the program were invited to complete pre- and postintervention surveys online. Participants completed the online surveys within two weeks of starting and then finishing the program. In addition, immediately after the conclusion of day two of the program, participants were invited to complete a paper-based program evaluation. Submission of surveys was taken as consent.

\section{Data collection}

A three-phase data collection process was undertaken as per Figure 1. As outlined earlier, only the first two phases are reported in this study. 


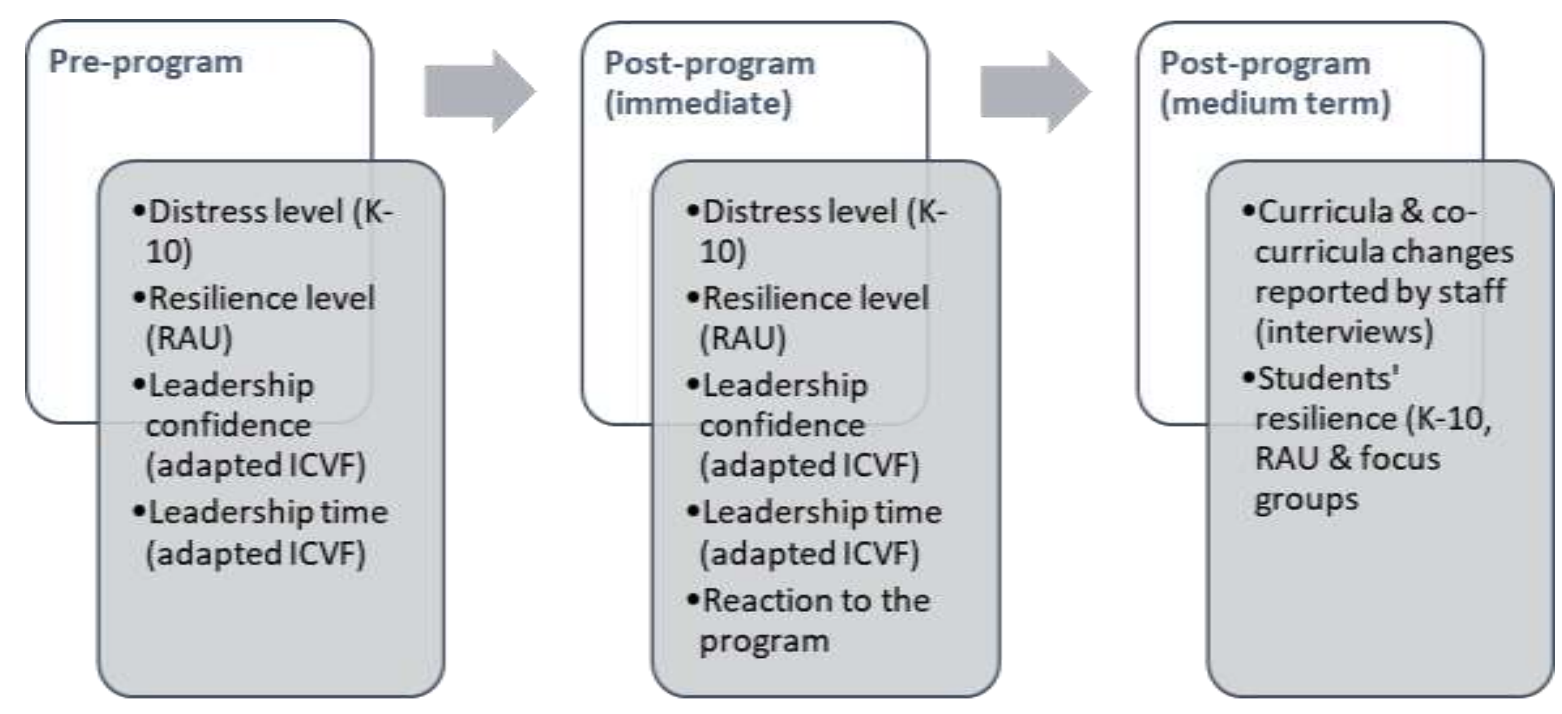

Figure 1: Data Collection Process

RAU = Resilience at University; ICVF = Integrated Competing Values Framework

Resilience and distress levels of program participants were gathered using the pre-and postintervention online surveys. The online survey comprised demographic questions, including a question on whether participants had experienced a period of adversity in the previous six months and their perceived impact of this. The survey also incorporated the validated Resilience at University (RAU) scale (Turner, Holdsworth, \& Scott-Young, 2017) and the Kessler Psychological Distress (K-10) scale (Kessler et al., 2002). A leadership questionnaire, based on the six roles of the Integrated Competing Values Framework (Vilkinas \& Cartan, 2006), was developed by the project team as part of the needs assessment. Participants created a personal code to ensure their data was anonymous, while allowing for pre and post surveys to be matched.

The 19-statement RAU scale (Turner et al., 2017), designed for use with higher education students, is comprised of seven factors: Finding your calling (FYC), Interacting Cooperatively (IC), Living Authentically (LA), Managing Stress (MS), Building Networks (BN), Maintaining Perspective (MP), and Staying Healthy (SH). To adapt the scale for use with university staff two minor word changes were made. For the item I often ask for feedback so that I can improve my university performance, the word 'university' was changed to 'work'. For the item I have a strong and reliable network of supportive students at university, the word 'students' was changed to 'colleagues'. The RAU uses a six-point Likert scale from 0 (strongly disagree) to 5 (strongly agree). The K-10 (Kessler et al., 2002) is a widely used measure to screen for psychological distress. It consists of ten questions about the level of anxiety and depressive symptoms experienced by the respondent in the previous four weeks. The tool uses a five-point Likert scale from 1 (none of the time) to 5 (all of the time) to measure the frequency of symptoms. The leadership questionnaire included 18 questions related to key leadership dimensions of the Integrated Competing Values Framework (Vilkinas \& Cartan, 2006). These dimensions were: leading others (e.g. developing staff capability), leading innovation and change (e.g. influencing and inspiring others), leading strategically (e.g. thinking strategically and having vision), managing operations (e.g. managing complex projects), and managing self (e.g. understanding self and others). Participants were asked to rate their confidence from low to high on a three-point Likert scale and the amount of time they spend on each of the leadership dimensions on a six-point Likert scale (1 represented not relevant to my current role and 6 represented I spend most of my time doing this).

A three-part paper-based survey, informed by Kirkpatrick's level I reaction survey tool (Kirkpatrick Partners, 2009), was provided to participants as part of the program's quality improvement process. Part one of the survey focused on the learning environment, course materials, relevance, delivery, and overall course satisfaction and impression. Participants were asked to rate their experience on a four-point Likert scale (1 represented strongly disagree and 4 represented strongly agree). Part two

Brewer, M., Lane, M., Carter, A., Barnard, S., \& Ibrahim, O. (2019). Evaluation of a leadership development program to enhance university staff and student resilience. Journal of Teaching and Learning for Graduate Employability, 10(2), $136-151$. 
of the survey focused on the participants' energy for change, specifically their confidence and commitment to applying their learning in the workplace. A ten-point Likert scale (1 represented not confident/committed at all and 10 represented extremely confident/committed) was utilised. Qualitative comments were invited throughout part one and two of the survey. Part three comprised open-ended questions that invited participants to reflect on the anticipated barriers to implementing their learning, potential strategies to overcome these barriers, outcomes they hoped to achieve from the program and the potential impact of the program on their organisation.

\section{Ethics statement}

This study was approved by the human research ethics committee of each of the three participating universities (approval number HRE2017-0439).

\section{Data analysis}

Data analysis was conducted using SPSS v21 to obtain demographic descriptive statistics and independent sample t-tests and mean comparisons for pre- and post-intervention scores. Qualitative comments from the surveys were analysed via NVIVO software version 12 .

\section{Results}

\section{Demographics}

Of the 58 program attendees, 38 staff completed the online pre-intervention survey and 17 completed the online post-intervention survey. Females comprised over $83 \%$ of the respondents (Table 2). Given the majority of participants were from a health-related course including physiotherapy, occupational therapy, speech pathology, psychology and nursing the high percentage of females was not surprising. For example, the profile of staff at Curtin's Faculty of Health Sciences from 2013 to 2017 indicated 75\% were female. The term 'exercise science' was used to capture staff from exercise science, exercise physiology, human movement and exercise, and sports and rehabilitation science. Courses categorised as 'other' included staff involved in learning design, creative industries, and internships. A number of staff (e.g. $28 \%$ pre-intervention) did not to specify the course they were involved with, many of whom were professional staff who worked across multiple courses. Nearly half (44\%) of the pre-intervention respondents, and just over threequarters $(76 \%)$ of the post-intervention respondents, indicated they were currently involved in an academic leadership and/or management role (e.g. unit or course coordinator, professional staff manager role). The vast majority of pre- and post-intervention respondents had over two years of academic experience, with approximately two thirds having more than five years' experience. Half of the respondents (49\%) had previously participated in a leadership program. Forty-one out of the 58 program participants (71\% response rate) completed the paper-based evaluation survey at the conclusion of the program.

Table 2: Survey Respondent Demographics

\section{Pre-intervention survey Post-intervention survey}

\section{Gender}

\begin{tabular}{lcc}
\hline Female & $34(87 \%)$ & $14(83 \%)$ \\
\hline Male & $5(13 \%)$ & $3(17 \%)$
\end{tabular}

Profession

Brewer, M., Lane, M., Carter, A., Barnard, S., \& Ibrahim, O. (2019). Evaluation of a leadership development program to enhance university staff and student resilience. Journal of Teaching and Learning for Graduate Employability, 10(2), $136-151$. 


\begin{tabular}{lcc}
\hline Health & $18(46 \%)$ & $11(64 \%)$ \\
\hline Exercise Science & $4(10 \%)$ & \\
\hline Education & $2(5 \%)$ & $2(12 \%)$ \\
\hline Business & $1(3 \%)$ & $1(6 \%)$ \\
\hline Other & $3(8 \%)$ & $3(18 \%)$ \\
\hline Not specified & $11(28 \%)$ & $1(6 \%)$ \\
\hline Academic experience & $5(13 \%)$ & $5(29 \%)$ \\
\hline $0-2$ years & $8(21 \%)$ & $5(29 \%)$ \\
\hline $2-5$ years & $11(28 \%)$ & $6(35 \%)$ \\
\hline $5-10$ years & $15(38 \%)$ & \\
\hline 10 years $>$ & &
\end{tabular}

\section{Staff resilience and distress}

Of the pre-intervention response group, 19 (51\%) reported experiencing a period of adversity or distress in the six months preceding the program. The perceived impact of this adversity varied, with $20 \%$ rating the impact as mild, $65 \%$ moderate and $15 \%$ severe. For the post-intervention respondents, not only the rate of experience of adversity was lower (41\%), but also the perceived impact, with $59 \%$ rating the impact as mild, $29 \%$ moderate and $12 \%$ severe. The details of this adversity were not requested. Self-reported levels of distress and resilience pre- and postintervention are outlined in Table 3. Staff members' distress level pre-intervention scored an average of 18.5 ( $S D=7.21$ ) on the K-10 scale, while the post-intervention cohort scored an average of 16.05 (SD = 5.11). It is worth noting that a normal score on the K-10 ranges from 15 to 20 (Kessler et al., 2002). Average scores on each of the seven resilience factors of the RUA scale for both pre and post staff cohorts are also reported in Table 3. Turner et al. (2017) state that the higher the resilience score the greater the resilience.

Table 3: Participants' Levels of Distress and Resilience Pre- and Post-Intervention

$\operatorname{PRE}(\mathrm{N}=38) \quad \operatorname{POST}(\mathrm{N}=17)$

\begin{tabular}{lcccccccccc}
\hline Scale/Subscale & Range & Min. & Max. & Mean & SD & Range & Min. & Max. & Mean & SD \\
\hline K-10 & 30 & 10 & 40 & 18.58 & 7.21 & 18 & 10 & 28 & 16.06 & 5.12 \\
\hline $\begin{array}{l}\text { RAU Finding } \\
\text { your calling }\end{array}$ & 20 & 4 & 24 & 18.68 & 4.60 & 10 & 14 & 24 & 19.89 & 2.42 \\
\hline $\begin{array}{l}\text { RAU Interacting } \\
\text { cooperatively }\end{array}$ & 5 & 7 & 12 & 9.92 & 1.26 & 6 & 6 & 12 & 9.47 & 1.81 \\
\hline $\begin{array}{l}\text { RAU Living } \\
\text { authentically }\end{array}$ & 10 & 8 & 18 & 14.16 & 2.39 & 8 & 10 & 18 & 14.89 & 2.00 \\
\hline $\begin{array}{l}\text { RAU Managing } \\
\text { stress }\end{array}$ & 18 & 0 & 18 & 11.55 & 4.29 & 10 & 8 & 18 & 13.65 & 2.60 \\
\hline
\end{tabular}

Brewer, M., Lane, M., Carter, A., Barnard, S., \& Ibrahim, O. (2019). Evaluation of a leadership development program to enhance university staff and student resilience. Journal of Teaching and Learning for Graduate Employability, 10(2), $136-151$. 


\begin{tabular}{lcccccccccc}
\hline $\begin{array}{l}\text { RAU Building } \\
\text { networks }\end{array}$ & 10 & 2 & 12 & 8.37 & 2.39 & 9 & 3 & 12 & 9.06 & 2.54 \\
\hline $\begin{array}{l}\text { RAU Maintaining } \\
\text { perspective }\end{array}$ & 17 & 1 & 18 & 9.26 & 4.66 & 14 & 1 & 15 & 10.65 & 3.55 \\
\hline $\begin{array}{l}\text { RAU Staying } \\
\text { healthy }\end{array}$ & 10 & 0 & 12 & 8.92 & 2.70 & 8 & 0 & 12 & 8.82 & 2.27 \\
\hline
\end{tabular}

RAU = Resilience at University

Interestingly, the highest levels of resilience were found for interacting cooperatively, finding your calling, living authentically, and staying healthy with scores at or above $75 \%$ of the maximum possible score. The lowest level of resilience was found for maintaining perspective which was at $50 \%$ of the maximum possible score. The overall results show an increase in resilience and decrease in distress scores following the intervention. However, due to the small sample size, the mean differences are not statistically significant, as reported in Table 4.

Table 4: Participants' Level of Distress and Resilience Pre- and Post- Intervention*

\begin{tabular}{lccccc}
\hline Scale/Subscale & $\begin{array}{c}\text { Mean } \\
\text { Difference }\end{array}$ & $\begin{array}{c}\text { Std. Error } \\
\text { Difference }\end{array}$ & $\mathbf{t}$ & df & $\begin{array}{c}\text { Sig. } \\
\text { (2-tailed) }\end{array}$ \\
\hline K-10 & 2.52 & 1.71 & 1.48 & 42.55 & .15 \\
\hline RAU Finding your calling & -1.20 & .95 & -1.27 & 51.39 & .21 \\
\hline RAU Interacting cooperatively & .45 & .48 & .93 & 23.25 & .36 \\
\hline RAU Living authentically & -.72 & .62 & -1.17 & 36.45 & .25 \\
\hline RAU Managing stress & .51 & .74 & .69 & 28.61 & .50 \\
\hline RAU Building networks & -.69 & .73 & -.95 & 29.20 & .35 \\
\hline RAU Maintaining perspective & -1.38 & 1.14 & -1.20 & 39.84 & .24 \\
\hline RAU Staying healthy & .10 & .70 & .14 & 36.23 & .89 \\
\hline
\end{tabular}

*Independent Sample T-tests (equal variances not assumed).

\section{Staff leadership practices}

Respondents' leadership practices, as aligned with the Integrated Competing Values Framework (Vilkinas \& Cartan, 2006), were measured via questions targeting confidence with, and time spent, on key leadership practices. While T-test results indicated average scores for perceived confidence and time showed an increase in the post-intervention cohort (Table 5), the mean differences are not significant (Table 6).

Table 5: Time Spent and Confidence of Participants' Leadership Capabilities Pre- and PostIntervention

\begin{tabular}{lcccccccccc}
\hline ICVF & \multicolumn{1}{c}{ PRE } \\
\cline { 2 - 13 } dimensions & Range & Min. & Max. & Mean & SD & Range & Min. & Max. & Mean & SD \\
\hline Time* & 48 & 44 & 92 & 67.58 & 12.04 & 36 & 55 & 91 & 71.06 & 11.91 \\
\hline Confidence** & 34 & 19 & 53 & 34.53 & 8.89 & 25 & 24 & 49 & 37.65 & 7.91 \\
\hline ICVF = Integrated Competing Values Framework \\
*Confidence measured on a scale from 1 to 3; ${ }^{* *}$ Time spent measured on a scale from 1 to 6
\end{tabular}


Table 6: Comparison of Time Spent and Confidence of Participants' Leadership Capabilities Preand Post-Intervention

\begin{tabular}{lccccc}
\hline & $\begin{array}{c}\text { Mean } \\
\text { Difference }\end{array}$ & Std. Error Difference & $\mathrm{t}$ & $\mathrm{df}$ & Sig. (2-tailed) \\
\hline ICVF Time & -3.48 & 3.49 & -.100 & 31.16 & .33 \\
\hline ICVF Confidence & -3.12 & 2.40 & -1.30 & 34.46 & .20 \\
\hline ICVF = Integrated Competing Values Framework & & & & \\
Note: T-Tests (Equal variances not assumed) & & & &
\end{tabular}

While time spent on the different leadership practices varied, pre-intervention the leadership domains where respondents spent moderate time (small amount to quite a bit) were: leading strategically, leading innovation and change, and managing operations. The most time was spent on managing self (quite $a$ bit to $a$ lot) and the least time on leading others (small amount). In relation to confidence in these leadership domains, pre-intervention almost half the participants $(42 \%)$ rated their confidence with leading others as low. Confidence with the leadership domains was generally moderate (50\% to $60 \%$ ) except for dealing with conflict, building and managing high performance teams, developing staff capacity, setting goals and objectives, and managing university resources and complex projects which received more low confidence ratings. Post-intervention more participants rated their confidence across all five domains as moderate with few low confidence ratings. Interestingly post-intervention $41 \%$ rated their confidence as high on building working relationships, effective communication, and modelling the organisation's values (all items under the domain of managing self). No other leadership practices received high ratings by more than $29 \%$ of participants post-intervention.

\section{Reaction to the program}

Forty-two of the 58 program participants (72\%) completed the paper-based evaluation survey at the conclusion of the second day which measured their reaction to the program (Kirkpatrick \& Kirkpatrick, 2006). Ratings were positive across all elements measured as demonstrated in Table 7 below. Qualitative comments were invited from participants with regard to the learning environment, course materials, relevance, delivery, and overall course impression and satisfaction. Further to this, participants commented on their energy for leading change, potential obstacles to this change and the outcome they wished to achieve. An overview of each aspect of the program, including supporting quotes, is outlined below.

Table 7: Summary of Staff Post-Program Paper-Based Evaluation Responses ( $N=42$ ).

\begin{tabular}{l|l|c|c|c|c|c|c}
\hline & $\begin{array}{l}\text { Overall } \\
\text { Course } \\
\text { Satisfaction }\end{array}$ & $\begin{array}{l}\text { Learning } \\
\text { Environment }\end{array}$ & $\begin{array}{l}\text { Course } \\
\text { Materials }\end{array}$ & $\begin{array}{l}\text { Course } \\
\text { Relevance }\end{array}$ & $\begin{array}{l}\text { Course } \\
\text { Delivery }\end{array}$ & $\begin{array}{l}\text { Course } \\
\text { Impression }\end{array}$ & $\begin{array}{l}\text { Overall } \\
\text { Confidence \& } \\
\text { Commitment }\end{array}$ \\
\hline Mean & 3.70 & 3.73 & 3.66 & 3.44 & 3.66 & 3.67 & 8 \\
\hline Median & 3.74 & 4 & 3.8 & 3 & 3.75 & 3.67 & 8 \\
\hline Mode & 4 & 4 & 4 & 4 & 4 & 4 & 8 \\
\hline
\end{tabular}

Note: Reaction to program, confidence and commitment to change measured immediately after program (reaction measured on a 1 to 4 scale, confidence \& commitment measured on 1 to 10 scale).

\section{Learning environment}

Overall, feedback regarding the learning environment was positive. For example, one participant commented: 
I found the environment very safe and inclusive and friendly.

\section{Course materials and relevance}

Many participants commented on the relevance of the course and course materials to their work and the usefulness of the resources, as demonstrated by the words of one participant:

Extensive resources; highly informative and appropriate for real-life application.

\section{Course delivery}

The most cited theme regarding the delivery of the program centred on the knowledge and skills of the facilitators, followed by the practical application of the program content. Participants commented:

$X$ was a great facilitator working at a manageable pace, catering for all interests, abilities and areas.

This course possibly provides only the surface of what can be gained with resilience (still so much to learn and be able to do). But, it is delivered in such an interactive way you take away (tools) you can apply immediately.

\section{Overall course impression and satisfaction}

The most frequent comments regarding participants' overall impression and satisfaction with the program were that it exceeded expectations. For example:

This course delivered more than I expected and was exactly what I needed right now.

Outstanding program. I especially liked that the resilience training was coupled with leadership development."

\section{Energy for change: Confidence and commitment}

Participants were asked to rate their confidence and commitment to apply what they had learned in the program to their work. Six participants $(14 \%)$ rated their confidence at a six or below on the $10-$ point Likert scale, with 36 rating their confidence greater than six (86\%). Those who rated their confidence or commitment at a six or below were asked to select the reasons for their choice with multiple responses possible. The two most common reasons for a reduced rating were not having the necessary resources and/or human support to apply their learning $(n=4)$. Three participants indicated they did not have a clear picture of what was expected of them. Two participants indicated they had other higher priorities, while another indicated they did not have the necessary knowledge and skills. In relation to commitment, 40 participants (95\%) rated their commitment greater than six.

\section{Obstacles to applying learning and potential solutions}

The most common barriers to implementing learning related to time-pressures including workload and competing priorities. Other barriers included concern over resistance to change from colleagues. The three most common solutions to these obstacles were: (1) utilise the support from others, particularly their peer-coaching group members; (2) focus on the reason for the change to gain buy-in from colleagues and senior staff; and (3) communicate widely and often. For example:

Addressing the many why's that underpin the need for student resilience.

\section{Desired outcomes and potential impact}

Not only did participants focus on enhancing student or graduate resilience, there was also a strong focus on enhancing their own resilience and the resilience of their colleagues. For example, when asked about their plans for the future, one participant remarked:

Brewer, M., Lane, M., Carter, A., Barnard, S., \& Ibrahim, O. (2019). Evaluation of a leadership development program to enhance university staff and student resilience. Journal of Teaching and Learning for Graduate Employability, 10(2), $136-151$. 
Increase my own resilience practices to increase my confidence and engage in new challenges.

Several comments linked enhanced resilience to specific outcomes, including fostering greater student independence, increasing student satisfaction, well-being, and university attendance. One participant commented:

Students have better resilience, so reduced drop-out from placement and less reliance on staff.

The most widely cited potential impact of the course related to student retention. The following participant quotes demonstrate the potential impacts of the program from across the three universities:

Students are more likely to stay in the course. Staff are more mindful of providing a supportive culture.

Increased satisfaction of students, who will then recommend [the University] to others as a place of excellence.

Resilient OT [occupational therapist]'s that build capacity within the profession and deliver high-quality healthcare.

\section{Discussion}

The higher education environment can be stressful for both students and staff. Although there has been increased attention on university students' mental health (Stallman, 2011) and resilience (Holdsworth et al., 2018) in recent years, the focus to date has been on teaching students to be resilient. This approach implies that resilience is an individual issue without consideration of the socio-cultural factors that impact on an individual's resilience (Brewer et al., 2019). Furthermore, this individualistic focus on students ignores the important part staff play as role models of resilience (Howe, Smajdor, \& Stockl, 2012). This study addressed this gap by focusing not only on the resilience of students but also the staff who support them and the context in which they learn. The aim of this study therefore was to assess the quality and impact of a development program designed to enhance staff's capabilities for leading resilience enhancement within their work context. The program, piloted in three universities across Australia, assisted staff in understanding the nature and importance of resilience and the leadership practices that help drive change in the higher education context.

A critical element of our program was establishing whether the staff had the resilience to function as effective role models for students and colleagues. Given growing concern over excessive stress experienced by university staff (Robotham \& Julian, 2006), it was perhaps not surprising that half of the study participants reported experiencing a recent period of adversity and that most of these participants felt this had a moderate impact on them. Despite this adversity, prior to the program, the participants' average level of distress was within the normal range, but towards the upper limit of the K-10 scale (Kessler et al., 2002). While participants' level of distress was reduced after the program, the small sample size in the follow up survey (only $30 \%$ of the program participants) did not allow conclusions on this to be drawn. Previous research indicates psychological distress among faculty staff has become widespread (Kinman \& Wray, 2013; Shin \& Jung, 2014) and elevated levels of stress and burnout have impacted on academics' performance, productivity, absenteeism and turnover (Khan, Rasli, Yusoff, \& Ahmad, 2015). Similarly, Watts and Robertson's (2011) systematic review of burnout in university teaching staff found clear evidence of burnout, particularly for women, younger staff members and those teaching large volumes of students. While no direct correlations were drawn in the study based on gender, it is worth noting that $83 \%$ of respondents were female. In addition, the majority of staff were from health-related courses, a field with a high representation of females and major concerns about staff and student wellbeing (Brand et al., 2017).

Brewer, M., Lane, M., Carter, A., Barnard, S., \& Ibrahim, O. (2019). Evaluation of a leadership development program to enhance university staff and student resilience. Journal of Teaching and Learning for Graduate Employability, 10(2), $136-151$. 
In relation to the program participants' resilience, this appears to be the first study to use a resilience scale developed specifically for the higher education context (Turner et al., 2017). Participants' resilience prior to the program was high for sense of purpose (finding your calling), living authentically, cooperation and staying healthy. Their reduced score for managing stress, building networks and maintaining perspectives was noted as a concern by the research team. Following the program, all seven resilience subscales had mean scores above $71 \%$ of the maximum possible score. Firm conclusions cannot be drawn from this finding, however, as the resilience tool (Turner et al., 2017) has only been used with students and the establishment of its psychometric properties is still in the development phase. Furthermore, as for the distress scale, the post-program sample size was small. It is worth noting that to date, research on the health and wellbeing of higher education staff has tended to adopt a deficit model, focusing only on levels of distress, burnout, depression and other mental health conditions. Research that adopts a strengths-based approach by focusing on staff resilience has yet to be explored thus comparisons with other studies is difficult. One recent qualitative study by Darabi, Macaskill, and Reidy (2017), of 31 academic staff in a teaching-intensive university in the UK, did find staff utilised both positive and negative coping strategies to deal with increased work stress. The most common positive coping strategy was establishing good working relationships with colleagues, a strategy that was low for the pre-program participants (building networks) but a key focus of the intervention and improved post-program. Interestingly, the potential for relationships with work colleagues to have a significant impact on staff resilience was evident in Ovans' (2015) study of over 800 employees in the UK where $75 \%$ of respondents reported that managing difficult people and office politics were the biggest drains on their resilience. While the link between resilience and both social support such as relationships with colleagues (Luthar, 2015) and self-care (Winkel, Honart, Robinson, Jones, \& Squires, 2018) has been reported, further research on university staff resilience is needed.

Exploration of the participants' leadership practices, using an adaptation of the Integrated Competing Values Framework (Vilkinas \& Cartan, 2006), indicated participants felt they spent more time and were more confident with leading innovation and change, leading strategically and managing self. The majority of staff estimated they spent the least amount of time and had the lowest level of confidence with leading others. This differs from Vilkinas and Ladyshewsky's (2012) study of 90 academic program directors from four Australian universities, that found local people issues (leading others) was the key area of focus of these leaders, followed by 'getting the job done' (managing operations). Interestingly, exerting influence, developing networks outside of their local area and leading innovation and change were deemed to be of less importance and thus received less time and attention by these program directors (Vilkinas \& Ladyshewsky, 2012). This research finding differs from Vilkinas and Ladyshesky's (2012) study, at least prior to the program, with participants study lacking both confidence and focus on leading others. It should be noted though that comparison is difficult due to differences in positions; only $44 \%$ of the pre-program respondents were in an academic leadership and/or management role. Participants' postintervention ratings of increased time and confidence in relation to leadership, while not statistically significant due sample size, was pleasing. In particular, the increase in high confidence ratings for three of the five managing self items was worthy of note given previous research has indicated that this leadership domain is a predictor of leadership effectiveness (Vilkinas \& Ladyshewsky, 2012). Managing self was also a key element of the resilience program. Another finding worthy of note was that only $44 \%$ of participants described themselves as having a leadership or management role prior to the program. It appears this may have been due to a reluctance to identify themselves as a leader as, when asked to identify their role, $21 \%$ were unit coordinators, $27 \%$ course coordinators and, of the $39 \%$ who categorised themselves as 'other', half had roles including clinical coordinator, program director, head of department or had a combination of these roles. The percentage who identified themselves as a leader increased post-program from $44 \%$ to $76 \%$. It was unclear if this was due to them having broader view of the term leadership, more confidence in labelling themselves as a leader, or if the staff who remained in the program and opted to participate in the post-survey had a leadership role.

Brewer, M., Lane, M., Carter, A., Barnard, S., \& Ibrahim, O. (2019). Evaluation of a leadership development program to enhance university staff and student resilience. Journal of Teaching and Learning for Graduate Employability, 10(2), $136-151$. 
Participants were overwhelmingly positive about the quality and delivery of the program. They reported high levels of confidence and commitment to applying their learning on resilience and leadership in their work context. These findings align with other similar programs. For example, Steinert and colleagues' (2016) systematic review of 111 faculty development programs found high levels of satisfaction (reaction and enjoyment), increased levels of confidence, enthusiasm, knowledge and skills, as well as self-reported and observed changes in teaching practices. Similarly, Hauser, Weisweiler, and Frey's (2018) meta-analysis of academic development programs found overall means of 4.20 and 4.46 (on a 5-point scale) for reaction and satisfaction.

Encouraged to reflect on, rethink and reframe their own priorities and approach to teaching (academic staff) or their work (professional staff), and to facilitate change within their sphere of influence (Covey, 1989), participants identified the three major barriers to leading change as timepressure, lack of resources, and colleagues' resistance to or lack of buy-in with the proposed change. These barriers are reported widely elsewhere (e.g. Gregory \& Lodge, 2015; Lewis, 2019; Serdyukov, 2017). Participants proposed solutions to these barriers included: utilising the support of others, focusing on the reason for the change, and communicating widely and often. These aspects were all key elements of the leadership program and align with previous research that has demonstrated the critical role of institutional support and local leadership in managing staffs' workloads (Jaaskela, Hakkinen, \& Rasku-Puttonene, 2017). All three strategies also align with change leadership experts including Harvard University Professor John Kotter (2012) and his eight accelerators for leading change.

The present study does have limitations. Only self-reported data was collected and analysed. While concerns have been raised about the validity of such data, these concerns have been challenged by Chan (2009) who argues that respondents' perceptions (e.g. of their own confidence, sense of commitment) are unlikely to be evident to others (peers, supervisors), and thus cannot be accurately measured by others. This research utilised both quantitative and qualitative data and forms part of a larger study which includes interviews and document audits with participants and students, all designed to increase the reliability and breadth of the program evaluation. Participant numbers were limited to those who attended the program, hence the sample size was relatively small, particularly following the intervention. Furthermore, the participants were predominantly from health faculties. While several other disciplines were represented, and three universities in different states of Australia involved, further research is needed to explore the extent to which the program is applicable to other fields and countries.

Another aspect worthy of further research is exploration of the enablers and obstacles staff encountered in translating the knowledge and skills gained during the program to leading curricula and co-curricula change. In addition, research is needed into the impact of these changes on student resilience and other areas of university life related to resilience such as the achievement of learning outcomes, retention, and health and wellbeing.

To conclude, university staff play a critical role in helping to build the resilience of their students. The program informed staff of strategies to enhance their own resilience so that they could effectively model resilience and actively assist students in the development of their resilience. A curriculum framework to support staff embedding resilience engagement within their curriculum is in the final stages of development and will be added to the program website referred to earlier. The program's replicability and reach beyond the initial pilots reported here was ensured through the dissemination of workshop resources on a dedicated website. Universities are encouraged to adopt a similar approach to student wellbeing that focuses not only on addressing mental health problems but also on enhancing resilience. Further to this, institutions and individual academic and professional staff need to view resilience as both an issue of the socio-cultural context as well as the individual. 


\section{Acknowledgements}

The authors acknowledge the Australian Technology Network for funding the research and the staff who participated in the study. Furthermore, we wish to thank the other members of the project team for their contribution: Michelle Donaldson, Gisela Van Kessel, Brooke Sanderson, Sonia Ferns, Alan Reubenson, Sharon Maresse, Bernadine Cooper and Fiona Naumann.

\section{Declaration of interest}

The research reported in this paper was supported by a grant from the Australian Technology Network.

\section{References}

Bahia, S., Freire, I., Estrela, M., Amaral, A., \& Santo, J. (2017). The Bologna process and the search for excellence: Between rhetoric and reality: The emotional reactions of teachers. Teaching in Higher Education, 22(4), 467-482. doi:10.1080/13562517.2017.1303471

Behari-Leak, K. (2017). New academics, new higher education contexts: A critical perspective on professional development. Teaching in Higher Education, 22(5), 485-500. doi:10.1080/13562517.2016.1273215

Boud, D., \& Brew, A. (2013). Reconceptualising academic work as professional practice: Implications for academic development. International Journal for Academic Development, 18(3), 208-221. doi:/10.1080/1360144X.2012.671771

Brand, S., Thompson Coon, J., Fleming, L., Carroll, L., Bethel, A., \& Wyatt, K. (2017). Whole-system approaches to improving the health and wellbeing of healthcare workers: A systematic review. Plos One, 12(12), e0188418. doi:10.1371/Journal.Pone.0188418

Brewer, M., van Kessel, G., Sanderson, B., Naumann, F., Lane, M., Reubenson, A., \& Carter, A. (2019). Resilience in higher education students: A scoping review. Higher Education Research and Development, 38(6), 1105-1120. doi:10.1080/07294360.2019.1626810

Chalmers, D., Cummings, R., Elliott, S., Stoney, S., Tucker, B., Wicking, R., \& de St Jorre, T. (2014). Australian university teaching criteria and standards project. Canberra, A.C.T: Australian Government Office for Teaching and Learning. Retrieved from http://www.olt.gov.au/ResourceAustralian-University-Teaching-Criteria-And-Standards

Chan, D. (2009). So why ask me? Are self-report data really that bad? In C. Lance \& R. Vandenberg (Eds.), Statistical and methodological myths and urban legends: Doctrine, verity and fable in the organizational and social sciences (pp. 309-336). New York: Taylor \& Francis.

Covey, S. (1989). The 7 habits of highly effective people: Powerful lessons in personal change. New York: Fireside.

Darabi, M., Macaskill, A., \& Reidy, L. (2017). A qualitative study of the UK academic role: Positive features, negative aspects and associated stressors in a mainly teaching-focused university. Journal of Further and Higher Education, 41(4), 566-580. doi:10.1080/0309877X.2016.1159287

Dickinson, M. J., \& Dickinson, D. A. (2015). Practically perfect in every way: Can reframing perfectionism for high-achieving undergraduates impact academic resilience? Studies in Higher Education, 40(10), 1889-1903. doi.org/10.1080/03075079.2014.912625

Gregory, M., \& Lodge, J. (2015). Academic workload: The silent barrier to the implementation of technology-enhanced learning strategies in higher education. Distance Education, 36(2), 210 230. doi:10.1080/01587919.2015.1055056

Gu, Q., \& Day, C. (2013). Challenges to teacher resilience: Conditions count. British Educational Research Journal, 39(1), 22-44. doi:10.1080/01411926.2011.623152

Hauser, A., Weisweiler, S., \& Frey, D. (2018). Because 'happy sheets' are not enough: A meta-analytical evaluation of a personnel development program in academia. Studies in Higher Education, 1-16. doi:10.1080/03075079.2018.1509306

Brewer, M., Lane, M., Carter, A., Barnard, S., \& Ibrahim, O. (2019). Evaluation of a leadership development program to enhance university staff and student resilience. Journal of Teaching and Learning for Graduate Employability, 10(2), $136-151$. 
Higher Education Standards Panel. (2017). Improving retention, completion and success in higher education, Higher Education Standards Panel Discussion Paper. Canberra, A.C.T: Australian Government Department of Education and Training.

Hoffman, R. (2017). Foreword. In I. Kinchin \& N. Winstone (Eds.), Pedagogic frailty and resilience in the university (pp. ix-xi). Rotterdam: Sense Publishers.

Holdsworth, S., Turner, M., \& Scott-Young, C. (2018). Not drowning, waving. Resilience and university: A student perspective. Studies in Higher Education, 43(11), 1837-1853. doi:10.1080/03075079.2017.1284193

Howe, A., Smajdor, A., \& Stockl, A. (2012). Towards an understanding of resilience and its relevance to medical training. Medical Education, 46(4), 349-356. doi:10.1111/j.1365-2923.2011.04188.x

Humburg, M., van der Velden, R., \& Verhagen, A. (2013). The employability of higher education graduates. Maastricht: Publications Office of the European Union.

Jääskelä, P., Häkkinen, P., \& Rasku-Puttonen, H. (2017). Supporting and constraining factors in the development of university teaching experienced by teachers. Teaching in Higher Education, 22(6), 655-671. doi:10.1080/13562517.2016.1273206

Kessler, R., Andrews, G., Colpe, L., Hiripi, E., Mroczek, D., Normand, S-L., ... \& Zaslavsky, A. (2002). Short screening scales to monitor population prevalences and trends in non-specific psychological distress. Psychological Medicine, 32(6), 959-976. doi:10.1017/\$0033291702006074

Khan, F., Rasli, A., Yusoff, R. \& Ahmad, A. (2015). Do demographics make a difference to job burnout among university academicians? International Journal of Economics and Financial Issues, 5(1S), 229-237. Retrieved from https://dergipark.org.tr/ljefi/lssue/31972/352283

Kinman, G., \& Wray, S. (2013). Higher stress: A survey of stress and well-being among staff in higher education. London, UK: University and College Union.

Kirkpatrick, D., \& Kirkpatrick, J. (2006). Evaluating training programs: The four levels (3rd ed.). San Francisco: BK Publishers.

Kirkpatrick Partners. (2009). Hybrid course evaluation form. Retrieved from https://www.kirkpatrickpartners.com/resources

Kotter, J. (2012). Leading change. Boston: Harvard Business Press.

Larcombe, W., Finch, S., Sore, R., Murray, C. M., Kentish, S., Mulder, R. A., ... \& Williams, D. A. (2016). Prevalence and socio-demographic correlates of psychological distress among students at an Australian university. Studies in Higher Education, 41(6), 1074-1091. doi.org/10.1080/03075079.2014.966072

Leppin, A. L., Bora, P. R., Tilburt, J. C., Gionfriddo, M. R., Zeballos-Palacios, C., Dulohery, M. M., ... \& Montori, V. M. (2014). The efficacy of resiliency training programs: A systematic review and meta-analysis of randomized trials. PloS one, 9(10), e111420. doi:10.1371/Journal.Pone.0111420

Lewis, L. (2019). Organizational change: Creating change through strategic communication. Hoboken, NJ: John Wiley \& Sons.

Luthar, S. (2015). Resilience in development: A synthesis of research across five decades. Developmental Psychopathology: Volume Three Risk, Disorder, and Adaptation, 739-795. doi:10.1002/9780470939406.Ch20

Mansfield, C., Beltman, S., Weatherby-Fell, N., \& Broadley, T. (2016). Classroom ready? Building resilience in teacher education. In R. Brandenburg, S. McDonough, J. Burke, \& S. White (Eds.), Teacher education: Innovation, intervention and impact (pp. 211-229). Singapore: Springer.

Mårtensson, K., \& Roxå, T. (2016). Leadership at a local level: Enhancing educational development. Educational Management Administration \& Leadership, 44(2), 247-262. doi:0.1177/1741143214549977

McLafferty, M., Mallet, J., \& McCauley, V. (2012). Coping at university: The role of resilience, emotional intelligence, age and gender. Journal of Quantitative Psychological Research, 1, 1-6.

Mula, I., Tilbury, D., Ryan, A., Mader, M., Dlouha, J., Mader, C., ... \& Alba, D. (2017). Catalysing change in higher education for sustainable development: A review of professional development initiatives for university educators. International Journal of Sustainability in Higher Education, 18(5), 798820. doi:10.1108/IJSHE-03-2017-0043

Ortega-Maldonado, A., \& Salanova, M. (2018). Psychological capital and performance among undergraduate students: The role of meaning-focused coping and satisfaction. Teaching in Higher Education, 23(3), 390-402. doi:10.1080/13562517.2017.1391199

Brewer, M., Lane, M., Carter, A., Barnard, S., \& Ibrahim, O. (2019). Evaluation of a leadership development program to enhance university staff and student resilience. Journal of Teaching and Learning for Graduate Employability, 10(2), $136-151$. 
Ovans, A. (2015). What resilience means, and why it matters. Harvard Business Review, 5. Retrieved from https://hbr.org/2015/01/what-resilience-means-and-why-it-matters

Pidgeon, A. M., Rowe, N., Stapleton, P., Magyar, H., \& Lo, B. (2014). Examining characteristics of resilience among university students: An international study. Open Journal of Social Sciences, 2(11), 14. doi:10.4236/Jss.2014.211003

Rahat, E., \& Ilhan, T. (2016). Coping styles, social support, relational self-construal, and resilience in predicting students' adjustment to university life. Educational Sciences: Theory and Practice, 16(1), 187-208. Doi:10.12738/estp.2016.1.0058

Robotham, D., \& Julian, C. (2006). Stress and the higher education student: A critical review of the literature. Journal of Further and Higher Education, 30(2), 107-117. doi:10.1080/03098770600617513

Ryan, M. L., Shochet, I. M., \& Stallman, H. M. (2010). Universal online interventions might engage psychologically distressed university students who are unlikely to seek formal help. Advances in Mental Health, 9(1), 73-83. doi.org/10.5172/jamh.9.1.73

Serdyukov, P. (2017). Innovation in education: What works, what doesn't, and what to do about it? Journal of Research in Innovative Teaching \& Learning, 10(1), 4-3. doi:10.1108/JRIT-10-20160007

Shin, J. C., \& Jung, J. (2014). Academics job satisfaction and job stress across countries in the changing academic environments. Higher Education, 67(5), 603-620. doi:10.1007/S10734-013-9668-Y

Stallman, H. M. (2011). Embedding resilience within the tertiary curriculum: A feasibility study. Higher Education Research and development, 30(2), 121-133. doi.org/10.1080/07294360.2010.509763

Stallman, H. M., \& Hurst, C. P. (2016). The university stress scale: Measuring domains and extent of stress in university students. Australian Psychologist, 51(2), 128-134. doi:10.1111/Ap.12127

Steinert, Y., Naismith, L., \& Mann, K. (2012). Faculty development initiatives designed to promote leadership in medical education, a BEME systematic review: BEME guide No. 19. Medical Teacher, 34(6), 483-503. doi:10.3109/0142159X.2012.680937

Steinert, Y., Mann, K., Anderson, B., Barnett, B. M., Centeno, A., Naismith, L., ... \& Ward, H. (2016). A systematic review of faculty development initiatives designed to enhance teaching effectiveness: A 10-year update: BEME Guide No. 40. Medical Teacher, 38(8), 769-786. doi.org/10.1080/0142159X.2016.1181851

Sunderland, M., Mahoney, A., \& Andrews, G. (2012). Investigating the factor structure of the Kessler Psychological Distress Scale in community and clinical samples of the Australian population. Journal of Psychopathology and Behavioral Assessment, 34(2), 253-259. doi.org/10.1016/i.brat.2012.03.005

Turner, M., Holdsworth, S., \& Scott-Young, C. (2017). Resilience at university: The development and testing of a new measure. Higher Education Research and Development, 36(2), 386-400. doi:10.1080/07294360.2016.1185398

Vilkinas, T., \& Cartan, G. (2006). The integrated competing values framework: Its spatial configuration. Journal of Management Development, 25(6), 505-521. doi:10.1108/02621710610670092

Vilkinas, T., \& Ladyshewsky, R. (2012). Leadership behaviour and effectiveness of academic program directors in Australian universities. Educational Management Administration \& Leadership, 4O(1), 109-126. doi:10.1177\%2F1741143211420613

Watson, R., Deary, I., Thompson, D., \& L, Gi. (2008). A study of stress and burnout in nursing students in Hong Kong: A questionnaire survey. International Journal of Nursing Studies, 45(10), 1534-1542. doi:10.1016/J.ljnurstu.2007.11.003

Watts, J., \& Robertson, N. (2011). Burnout in university teaching staff: A systematic literature review. Educational Research, 53(1), 33-50. doi:10.1080/00131881.2011.552235

Willumsen, E. (2006). Leadership in interprofessional collaboration: The case of childcare in Norway. Journal of Interprofessional Care, 20(4), 403-413. doi:10.1080/13561820600874692

Winkel, A., Honart, A., Robinson, A., Jones, A., \& Squires, A. (2018). Thriving in scrubs: A qualitative study of resident resilience. Reproductive Health, 15(1), 53. doi:10.1186/S12978-018-0489-4

Zábrodská, K., Mudrák, J., Šolcová, I., Květon, P., Blatný, M., \& Machovcová, K. (2018). Burnout among university faculty: The central role of work-family conflict. Educational Psychology, 38(6), 800819. doi:10.1080/01443410.2017.1340590

Brewer, M., Lane, M., Carter, A., Barnard, S., \& Ibrahim, O. (2019). Evaluation of a leadership development program to enhance university staff and student resilience. Journal of Teaching and Learning for Graduate Employability, 10(2), $136-151$. 